\title{
Emotional distress with dementia: A systematic review using corpus-based analysis and meta-ethnography
}

\section{Stephanie Petty ${ }^{\mathbf{1} 2}$ (D) | Kevin Harvey ${ }^{3}$ | Amanda Griffiths ${ }^{2}$ | Donna Maria Coleston ${ }^{2}$ | Tom Dening ${ }^{2}$ (1)}

${ }^{1}$ The Retreat, York, UK

${ }^{2}$ Division of Psychiatry and Applied

Psychology, School of Medicine, University of Nottingham, Institute of Mental Health,

Nottingham, UK

${ }^{3}$ School of English, University of Nottingham, University Park, Nottingham, UK

Correspondence

Stephanie Petty, The Retreat, Heslington Rd, York YO10 5BN, UK.

Email: spetty@theretreatyork.org.uk

Objective: More understanding is needed about the emotional experiences of dementia from the perspective of the individual. This understanding can then inform the provision of health care to meet individual needs. This systematic review aimed to present all available descriptions of emotional distress and explanations for emotional distress experienced by individuals with dementia, articulated personally and by others.

Methods: A systematic mixed-method review identified literature that was screened and quality appraised. Data were analysed quantitatively and qualitatively using corpus-based methods and meta-ethnography.

Results: The 121 included studies showed that individuals with dementia have expressed emotional distress comprehensibly. Family, professional caregivers, clinicians, and academic writers have also observed and described extreme emotional experiences. Feeling fearful and lonely were predominant and show the importance of anxiety in dementia. Explanations for emotional distress included threats to universal, human needs for identity, belonging, hope, and predictability.

Conclusions: The variable and personal emotional experiences of individuals with dementia are well described and should not continue to be overlooked. Limitations, future research, and clinical implications are discussed.

\section{KEYWORDS}

anxiety, corpus linguistics, dementia, emotion, meta-ethnography

\section{1 | INTRODUCTION}

Emotional distress is a universal experience for individuals with dementia, which is compelling and yet almost entirely overlooked in research. By this, we mean the variable, responsive, and normal range of emotions, which are intricately linked with a person's experiences following the onset of dementia. This is not to overlook the extensive work into emotional symptoms and psychiatric disorders, such as anxiety and depression, ${ }^{1,2}$ but to explore further the variable and personally meaningful descriptions of emotion, ${ }^{3}$ the causes of a range of emotions, and what individualised responses in dementia care might look like. We present a systematic review of the available literature concerning, first, how emotional distress has been described and, second, the explanations offered for emotional distress, as reported by individuals with dementia and as observed by others.

Within the past 25 years, the emotional experience of dementia has received attention in the form of theory and clinical reflections. Notable examples have been the defining of person centred care ${ }^{4}$ and the application of attachment theory ${ }^{5}$ and psychoanalytic theory. ${ }^{6-8}$ Unfortunately, these understandings have not attracted systematic study and have had little influence on routine health care, whereby commonplace emotions then receive care, although the value of psychological interventions for specific mood disorders is a welcome addition. ${ }^{9}$ In 1996, Magai et al noted the lack of research on emotional expression, stating that the field of dementia research was "ripe" for this research and referred to an impetus to inform dementia care with an individual's emotional needs. ${ }^{10}$ The underrepresentation of the emotional experience of dementia in influential guidelines for care provision suggests that further research is welcome. ${ }^{11}$ Johansson and Grimby noted "the overemphasis on physical care and a failure to see these patients as individuals with feelings, beliefs, and values." ${ }^{12}$ We reiterate that minimizing the emotional experience of dementia, negative emotional experiences in particular, can limit understanding of the individual and their care needs. ${ }^{13}$ 
Dementia is experienced by many people, and its impact is considerable. ${ }^{14}$ The majority of individuals with dementia display behavioural and emotional symptoms, such as agitation and apathy, increasingly in moderate-to-severe presentations. ${ }^{15}$ However, there has been an assumption that a more robust understanding of emotion prevails than is actually the case because of the predominant use of symptom labels.

\section{1 | Definition and causes of distress}

A broad definition of emotional distress was employed to capture diverse expressions of distress, which acknowledged definitions used across a range of health conditions. ${ }^{16}$ We view emotional distress as an expression of negative emotion, with some marker of intensity or urgency; this excludes emotional experiences that could be considered negative but not necessarily distressing, such as boredom or displeasure. A clear definition in this study was different from how "distress" has been used to label a comprehensive and indiscriminate range of experiences for individuals with dementia to date. ${ }^{14,17-20}$ Similarly, as with the under-acknowledgement of the prevalence of emotional distress for individuals with dementia, there has been an under-acknowledgment of the causes of distress that differ for each individual, ${ }^{20}$ despite the often complex and accompanying support needed. ${ }^{21}$

To our knowledge, this was the first attempt to review systematically what is understood of the experience of emotional distress for individuals with dementia within the available literature. We therefore consider all viewpoints of emotional distress. This includes self-report accounts as it has been reliably demonstrated that individuals with dementia of any severity are able to communicate emotional distress. ${ }^{10,22}$ It also includes papers written by academic writers as these contribute to the overall picture. The research questions were: "How can emotional distress be characterised for individuals with dementia? What descriptions of emotional distress exist? What explanations for emotional distress exist?"

\section{2 | METHODS}

\section{1 | Search method}

A systematic, mixed studies review was conducted. A review protocol was developed that adhered to 7 stages for completing a systematic review, including (1) stating the research question, (2) setting advance eligibility criteria for the inclusion of literature, (3) describing the search strategy, (4) describing the methods for retrieving and screening literature, (5) appraising quality and risk of bias, (6) data extraction, and (7) data synthesis. ${ }^{23}$ Literature was included whereby primary subjects were human, diagnosed with dementia of any severity or diagnostic type, of any age; any study design or written account was included, published in English, with no date restriction prior to 31 January 2016; an original description or explanation of the emotional distress of individuals with dementia was provided from any viewpoint. In addition to available self-reported accounts of distress, information from family, friends, professional caregivers, and researchers was included. Descriptions or explanations were not limited to primary

\section{Key points}

- Individuals with dementia have expressed their personal experiences of emotional distress comprehensibly.

- These descriptions of emotion move beyond our current understandings of emotional symptoms and psychiatric disorders in dementia.

- Feeling fearful or anxious is the most prominent experience of emotional distress for people with dementia.

- These findings could inform our understanding of dayto-day experiences of people with dementia and an important aspect of their care needs.

\section{0}

data; novel descriptions or explanations by authors were included, such as accumulated understanding from clinical experience or original theory development.

Twelve electronic databases were searched for academic and commercial publications and grey literature (see Supplementary Table S1). The reference lists of retrieved articles were hand-searched. Search terms included (1) "dementia" or "Alzheimer's" and (2) synonyms of emotion, informed by Medical Subject Headings and subject headings/thesaurus terms.

Two authors independently screened $1 \%$ of titles as informed by a power analysis calculation that required 456 titles to be jointly reviewed to demonstrate substantial agreement. Agreement was excellent using Cohen's $\mathrm{k}(\mathrm{k}=.84)$. Two raters screened $5 \%$ of abstracts. Agreement was initially "poor" $(\kappa=.13)$ because 1 rater was more inclusive of literature. Each was discussed, and all disagreed upon abstracts were retained. The full research group collectively screened full texts. Screening was determined by a detailed inclusion checklist (see Supplementary Table S2). Duplicate literature was removed, first electronically using EndNote bibliography software, and second by manual searching. A flowchart illustrating the inclusion and exclusion of literature is provided in Supplementary Figure S1. A total of 64898 retrieved titles including duplicates contained 121 studies for inclusion.

\section{2 | Quality appraisal}

A systematic approach to quality appraisal was employed, which allowed the appraisal of any study design. A quality appraisal checklist was produced from existing tools (see Supplementary Table S3). Two reviewers independently quality appraised $5 \%$ of full texts to improve reliability. Agreement was good using Cohen's $\mathrm{k}(\mathrm{k}=.75)$. The main reason for disagreement was whether a study presented adequate evidence for and against the findings. One author (SP) appraised all remaining studies. All literature was retained; however, the findings of studies appraised to be of higher quality were prioritised in the analysis and were supplemented by literature with lower quality ratings. ${ }^{24}$ 


\section{3 | Data synthesis}

Each study was read for concepts, which were descriptions or explanations of emotional distress, and formed the raw data for the synthesis. A "concept" was an attempt to reach the simplest description of the whole account, while preserving the original meaning. ${ }^{25}$ Large chunks of text were extracted by 1 author (SP) and refined by the whole research group. An extraction table was used alongside continuous referencing back to the original papers.

Two methods of analysis were employed in attempt to best represent the data produced by the search: for the descriptions of distress, corpus-based analysis was employed. For the explanations of distress, meta-ethnography was employed.

\section{4 | Descriptions of distress}

Corpus-based analysis is a well-recognised approach for analysing large samples of written text, or "corpora," ${ }^{26}$ firstly by applying quantitative methods to uncover patterns in language use, and secondly by using qualitative methods to interpret the patterns. Corpus-based linguistics has been used in a range of health communication contexts, including psychiatric contexts. ${ }^{27}$ A "corpus" can be compiled to investigate a particular variety of language used by certain people or in a particular context. ${ }^{27}$ Here, a new, specialised corpus was compiled from texts determined by the search strategy because this collection of texts did not previously exist. ${ }^{26}$ The specialised corpus contained 25163 words. This featured all extracted study data from the 121 studies, published between 1984 and 2015, with a median year of publication of 2006. Publications were journal articles (101), book sections (18), a professional group periodical, and a charity document. Within these publications, a variety of written and spoken genres were represented: case report, case note review, clinician reflection, diary, essay, experiment, field, group and individual observation, group interview, individual interview, recordings of clinical meetings, structured questionnaire, therapy transcripts, and unstructured conversations. The full study list and the methodological features of each study are available in Supplementary Table S5.

Corpus-based analysis was used to produce an objective and original description of distress that reduced the a priori bias of researchers, because keywords and salient patterns of distress descriptions were generated purely computationally. ${ }^{26,28,29}$ WordSmith Tools ${ }^{30,31}$ was used because it has been widely supported as a corpus analysis package. $^{26,29}$ Keywords, collocation, and concordance analyses were employed.

Keywords were single words that occurred in the specialised corpus more frequently than would be expected in general language use. Hence, keyword analysis was used to show unusual or salient language that defined the descriptions of distress. The "keyness" of words was calculated by comparing the frequency of all words in the specialised corpus with their corresponding occurrence in a reference corpus, using log likelihood and log ratio tests. The British National Corpus was used as a reference corpus because it is considered to be large and representative of "normal" language, consisting of 100 million words and samples of both written and spoken texts, fiction and non-fiction, published and unpublished texts, including books, essays, journals, letters, and conversations. ${ }^{26,32}$ All distress descriptions, self-reported accounts, and other-reported accounts of distress were compared with the reference corpus to reveal differences in language use between the reporting groups.

Analysis of collocation assessed the strength of the relationship between the keywords and words that occurred as their neighbours and determined whether the relationship was statistically significant. The collocate list was sorted by "mutual information" (MI) scores, which took into account words that frequently occur generally, such as high-frequency grammar words, but only presented as collocates those words that occurred with the keyword with greater frequency than would be expected in general language use. ${ }^{31}$ Therefore, instead of showing high-frequency collocates such as "of" or "being," qualifiers such as "imminent" or "tomorrow" were shown. An MI score of $>3$ indicates a strong relationship between neighbouring words. ${ }^{33}$

Concordance lines showed excerpts of original text that displayed the wider textual contexts of keywords and their collocates. ${ }^{26,29}$

\section{5 | Explanations for distress}

Meta-ethnography ${ }^{25}$ was used to provide a comprehensive and usable summary of explanations for the emotional distress experienced by individuals with dementia. Meta-ethnography has been recognised as the most widely used and rigorous method for synthesising qualitative literature ${ }^{34-38}$ and an important method for synthesizing evidence to inform policy in nursing and health care. ${ }^{25,39}$ It offers a technique for systematically finding and mapping out ideas that exist within different literature. Meta-ethnography was considered to be appropriate for this research question because it is immediately concerned with the experiences of the individuals involved in the phenomenon of interest: the everyday, lived experiences of individuals with dementia. The analysis closely adhered to the available guidance. ${ }^{25,35-39}$

Explanations for distress were extracted and presented beneath 6 main concept categories. The emerging list of concepts was identified by the first author (S-P.) and agreed in continuous discussion with the whole research group. A second researcher (T:D:) reviewed the extracted data for $10 \%$ of studies to refine the concept categories. Studies could be represented across multiple categories.

The data extraction table and concept grid illustrating which concepts were represented within each study (see Supplementary Table S4) allowed initial decisions to be made about the relationships between studies and informed the selection of "reciprocal translation" analysis. ${ }^{25}$ Within each category, the literature was ordered by quality rating. ${ }^{25}$ The concepts of the first study (with the highest assigned quality rating) were compared with the concepts of the second study; then, the concepts of the first and second study with the concepts of the third study, and so on. In this way, all studies within each category were "translated" into each other using constant comparison.

\section{I RESULTS}

\section{1 | Description of studies}

A total of 121 studies met the inclusion criteria (see Supplementary Figure S1). The self-reported accounts of 906 individuals with 
dementia were represented, 399 family members, 135 professional caregivers, and 44 academic writers/researchers. The number of individuals with dementia represented indirectly by these viewpoints collectively was unquantifiable, but easily over 1000. A range of dementia diagnoses were included, though for the majority of studies, "dementia" was used without further elaboration. When stated, 44 studies represented individuals with a diagnosis of Alzheimer's disease, 13 with vascular dementia, 10 with mixed dementia diagnoses, 4 with multi-infarct dementia, 2 with frontal or fronto-temporal dementia, 2 with Dementia with Lewy bodies, 2 with Parkinson's dementia, and 1 study representing each of subcortical dementia, Korsakoff's dementia, Pick's disease, Creutzfeldt-Jakob disease, and AIDS dementia. In 18 studies (15\%), authors described moderate or moderate-to-severe dementia presentations, with all other studies describing probable, mild, or no description of severity. A range of living environments for individuals with dementia featured: when stated, 34 studies considered the experiences of individuals living within the community alone, with family, in a shared house or retirement complex, 16 studies considered individuals residing within a nursing home, 11 within residential care or supported accommodation, 5 within an inpatient psychiatric unit, 4 within a day care service, 3 within a hospital setting, and 1 within a hospice. Studies were conducted in 14 countries, with the majority conducted in the UK (34\%), the USA (29\%), and Sweden (12\%). Studies were published between 1984 and 2016. Although all studies contained explanations for emotional distress for individuals with dementia, only 18 (15\%) stated this as an explicit aim.

\subsection{Study quality}

The summarised quality scores for each study are available in Supplementary Table S5. An equal number of studies received high as low quality ratings. Both higher and lower quality studies represented a range of viewpoints, a range of dementia diagnoses, and were conducted in a range of countries. They also featured all 6 explanations for distress. However, it was noted that the majority of studies that represented moderate-to-severe dementia presentations $(94 \%, n=17)$ were rated as higher in quality, suggesting a specialist research area.

The most frequent reasons for lower quality ratings were omissions of methodological processes to ensure the reliability and validity of findings, such as controlling for or discussing confounding variables or discussing the representativeness of the sample. In addition, the relationship between the author and sample was infrequently considered, meaning that the viewpoints presented could be open to influence or bias without this being accounted for in the findings.

\section{3 | Descriptions of distress}

The most frequently occurring descriptions of distress in the T1 self-report and the other-report corpora are displayed in Table 1 as keywords. Only descriptions of distress are presented, with words such as "dementia," "I," and "her" omitted.

For self-reported descriptions of distress, feeling fearful was predominant, accounting for 5 of the 12 most frequent descriptions.
The log ratios displayed in Table 1 show how frequent keywords were; a log ratio of 1 shows that a keyword was twice as frequent than in the reference corpus, a log ratio of 2 shows that a keyword was 4 times as frequent, 3 was 8 times as frequent, and so on. ${ }^{31}$ "Fear," "worried," and "frightened" each had a log ratio of greater than 5, meaning they were 32 times more likely to occur in the self-report distress corpus than in general language. Taking the self-reported and other-reported descriptions of distress together, loneliness was assigned the second highest keyness value after descriptions of fear.

Comparing the self-reported and other-reported descriptions of distress, self-reported descriptions included "worried," "frightened," and "panic" in contrast to "anxious" or "anxiety." Similarly, individuals themselves used "tears" rather than "crying." "Distress" was used frequently by both groups, but more so within the other-report corpus. Therefore, when others described the distress of individuals with dementia, they tended to use summarised and surmised terms, such as "anxiety," "distress," "depression," and "agitation." Within the self-report corpus, the distress descriptions were more varied; distress keywords were dispersed, with fewer high frequency words as shown in the frequency column of Table 1, despite both corpora being of equal word count. The higher log ratio values in the otherreported descriptions also show the higher occurrence of a more limited selection of words. "Anxiety" and "distress" were 128 times more likely to occur in the other-report distress corpus than in general language. Both groups captured extreme emotional experiences, such as "panic," "despair," and "terror" within the most frequent descriptions.

Collocates, or neighbouring words to the keywords, from all distress descriptions showed markers of intensity and the individual nature of the emotional experience (Table 2). Examples were T2 "imminent," "extreme," "frequently," and "idiosyncratic," which collocated with "fear," "loneliness," and "distress." The high number of significant collocates also demonstrated a breadth of descriptions.

A selection of concordance lines for "fear," "loneliness," and "distress" are presented in Table 3. "Fear" occurred most frequently T3 with a qualifier of intensity (as shown in the analysis of collocation) or with a secondary emotional label to expand the description. For example, "alarming," "extreme," and "terrible" were used, as were "terror," "anguish," and "existential." Explanations for feeling fearful, such as fear of appearing to be a fool, fearing tomorrow, or fearing being with strangers are presented next.

\subsection{Explanations for distress}

Six explanations for distress were revealed, presented in Tables 4 and 5 , with example quotes to illustrate each concept. More detailed descriptions of each concept, supplemented with all study excerpts, are available in Supplementary Text S1.

Individuals with dementia and others provided all 6 explanations for distress. Individuals with dementia most frequently reported a negative social position to be a cause for distress, followed by changes to their sense of self. This differed from the most frequently reported explanations provided by others, which were change to the person's sense of self, followed by not having a relationship at the time of need. 
TABLE 1 Keywords in the descriptions of distress corpus (1. Self-reported and 2. Other-reported distress descriptions) ranked in order of keyword strength

\begin{tabular}{|c|c|c|c|c|c|}
\hline & \multicolumn{5}{|c|}{ 1. Self-reported distress descriptions } \\
\hline & Word & Frequency & RC Frequency & $\begin{array}{l}\text { Keyness } \\
\text { Log-likelihood }\end{array}$ & Log ratio \\
\hline 1 & Fear & 37 & 9845 & 193 & 5.17 \\
\hline 3 & Frightened & 16 & 2503 & 97 & 5.78 \\
\hline 4 & Lost & 27 & 18770 & 87 & 3.65 \\
\hline 7 & Panic & 11 & 2000 & 63 & 5.58 \\
\hline 8 & Angry & 13 & 3980 & 62 & 4.83 \\
\hline 9 & Loneliness & 8 & 575 & 61 & 6.92 \\
\hline 10 & Sad & 12 & 3304 & 60 & 4.98 \\
\hline \multirow{2}{*}{12} & \multicolumn{5}{|c|}{ 2. Other-reported distress descriptions } \\
\hline & Word & Frequency & RC Frequency & $\begin{array}{l}\text { Keyness } \\
\text { Log-likelihood }\end{array}$ & Log ratio \\
\hline 1 & Anxiety & 52 & 2609 & 414 & 7.20 \\
\hline 2 & Distress & 30 & 1446 & 242 & 7.25 \\
\hline 3 & Fear & 44 & 8945 & 230 & 5.18 \\
\hline 4 & Loneliness & 19 & 575 & 170 & 7.93 \\
\hline 5 & Anger & 26 & 3660 & 155 & 5.71 \\
\hline 6 & Anxious & 23 & 2984 & 140 & 5.83 \\
\hline 7 & Depression & 18 & 2247 & 111 & 5.88 \\
\hline 8 & Distressed & 13 & 607 & 105 & 7.30 \\
\hline
\end{tabular}

TABLE 2 Strong collocates of the keywords "fear," "loneliness," and "distress" with an MI score of >3. Grammatical collocates such as "of," "with," and "the" were omitted so only content collocates are displayed

\begin{tabular}{|c|c|}
\hline & Self- and other-reported \\
\hline Fear & $\begin{array}{l}\text { Tomorrow, generated, imminent, dreams, relating, conscious, starting, placed, unknown, remembering, dread, underlying, extreme, isolation, } \\
\text { agitation, failure, unconscious, alienation, dying, seen, fearful, terror, happen, uncertainty, losing, becoming, end, particularly, great, } \\
\text { memories, real, alone, deep, associated, sadness, words, dependency, mind, some, loneliness, burden, anxiety, control, left, might, } \\
\text { Alzheimer's, distress, experienced, participants, being, feelings, fears, going, something, anger, become, death, self, family, disease, } \\
\text { experience, loss, feeling, things, very, others, home }\end{array}$ \\
\hline
\end{tabular}

Loneliness Occur, extreme, frequently, isolation, uncertainty, experience, feelings, found, even, depression, participants, fear, loss, sense

Distress Idiosyncratic, withheld, worked, signs, particular, number, frustration, shock, diagnosis, experienced, anger, fear, felt, feelings, anxiety, dementia, know

\section{4 | DISCUSSION}

This mixed studies systematic review reported on the expressions of emotional distress from over 1000 people with dementia. It demonstrated that individuals with dementia have expressed their experiences of emotional distress using rich, varied, and personal language. Furthermore, emotional distress for individuals with dementia has been described in equal intensity by others, though with more ambiguous and surmised terms. Explanations for emotional distress were abundant and incorporated universal human needs. This understanding of "what emotional distress consists of" for individuals with dementia was demonstrated using the largest and most varied representation of viewpoints of the emotional experience of dementia to date. Viewpoints included individuals with dementia themselves, their families, professional caregivers, clinicians, and academic authors.

\section{1 | Interpretations of findings}

Fear and dementia: The results suggested that feeling fearful is the most prominent experience of emotional distress for people with 
TABLE 3 Concordance lines showing example descriptions of distress using the words "fear," "lonely/loneliness," and "distress" in context

Fear Participants shared their underlying fear of appearing to be a fool.. diagnosis includes a huge injection of fear... some fear runs deep into your inner being... fear of what will happen tomorrow... a deep existential fear that is starting to creep into my heart and my mind... like... I've got this terrible fear of someone taking my pills off me
Self-reported I fear being alone with a stranger who I don't know, maybe won't

\section{Other-reported}

She realizes that with alarming fear, she doesn't know why she is standing in front of her stove... the sense of isolation contributed to feelings of fear and terror, which were sometimes extreme.. mental, emotional and existential anguish that living and the fear and anticipation of death created... her eyes betrayed another emotion: Fear. I realized that she was terrified... it was a real fear that she would abandon him.

Lonely/loneliness It is quiet and lonely, but the silence, I have never liked... I do feel very Isolation and loneliness... intensified feelings of loneliness... holding lonely, and when you go out... I never tell her I'm lonely.... If I feel lonely, it's at night when I miss my wife... painfully lonely... I'm so lonely here... the sense of loneliness can be so overpowering.. feelings of loneliness and social isolation... feelings of guilt and loneliness overwhelmed me deep within herself the loneliness and the loss of the world she had known... the fear of loneliness can be the fear of being left alone... it is clear that loneliness can be a distressing experience... extreme loneliness... carers frequently mentioned an association between loneliness and memory loss

Distress Even worse when what you can remember causes additional distress!... frustration or distress felt... symptoms of psychological distress, for example, outbursts of anger, panic attacks... clearly experienced distress

\section{Signs of distress are idiosyncratic... with expressions of distress} centered on feelings of uncertainty... obvious signs of shock and distress... her scream tells of her distress... wailing loudly in a voice full of distress... expression of deep distress... that caused her particular distress
Featured within (Study ID):

$1,2,4,5,7,9,10,13,14,15,17,19,21,23,26,27,28,29,30$, $32,34,37,39,40,43,44,45,47,48,50,55,57,58,61,63,66$, $68,70,71,74,76,80,82,83,84,86,92,93,94,95,96,98,99$, $100,101,102,105,106,107,108,111,112,117,119,121$ (65 studies)

Social position

$1,2,3,4,7,8,13,14,17,18,21,22,23,26,29,30,36,39,40$ $41,43,45,50,51,52,53,55,58,64,66,67,71,78,79,81,83$, $85,86,87,88,89,90,93,94,95,98,100,101,102,104,106$, $115,116,118,120$ (55 studies)

Relational needs

$1,4,5,8,11,13,14,15,23,27,29,30,31,36,37,39,40,42,44$, $45,46,47,49,52,56,60,62,64,65,68,69,70,72,73,75,76$, $78,79,81,93,94,97,100,104,105,106,107,108,110,115$, 119, 121 (52 studies)

Future

$5,6,7,8,12,13,17,18,20,21,24,26,27,29,30,32,34,39,40$, $42,44,48,49,51,52,54,55,57,61,66,68,70,74,77,82,84$, $86,87,89,92,100,101,102,106,116,118,120,121$ (48 studies)

Physical environment $5,8,12,14,15,19,23,29,30,33,34,35,39,47,50,54,59,67$, $87,91,100,106,113,119$ (24 studies)

\author{
Perception \\ $1,8,16,17,25,30,38,40,41,43,47,54,76,100,103,109$, \\ $114,119,121$ (19 studies)
}

\section{Concept Examples}

"The whole disease is about insecurity and poor self-esteem" (84), "a nearly complete dismantling of the self I once knew" (44), "I was used to having a home" (82), "I who could move mountains!" (71), "helplessness to control this insidious thief who was little by little taking away my most valued possession, my mind" (30), "loss of the self, fear of dying twice" (106), "first of all, you are nobody" (48).

"Feeling excluded by others and society" (39), "I feel that I'm not much use to anybody" (22), "like a little girl admitting she had been naughty and had done something wrong" (39), "I'm a lot of rubbish now" (23), "all my enjoyment they took it away from me... everything I try or want to do" (89), "feared becoming a nuisance or burden" (21).

"I've no one here at all" (23), "feeling lonely despite being surrounded by lots of people" (45), "abandonment or betrayed" (31), "a terrified, disorganized, and uncontained infant" (29), "compounded by memory loss and not recalling visits from family and friends" (5).

"Disclosure of the diagnosis" (77), "feeling unreal, I think I was just in a vacuum" (48), "you have Alzheimer's" (120), "nightmares about the future" (48), "I thought that was the end of my life" (89), "downward spiral of hopelessness" (17), "fear of losing control of the mind" (39), "foreboding of what's in front of me" (42), "frightened that my mind had 'snapped"' (40), "the anticipation of death" (6).

"Too many stimuli in the ward" (14), "everything around them was moving too fast" (50), "confused by their environment" (47), "totally overwhelmed by new or complex environmental demands" (119), "she was constantly looking around nervously as people moved towards or around her" (8).

"Re-experiencing from childhood" (8), "unhappiness in personality" (43), "hallucinations" (17), "all the adrenaline rush, perspiration, rapid breathing, and heart pounding of a real situation" (30), "the floor suddenly heaved and swayed" (40). dementia, followed by feeling lonely. Fear was qualified as "imminent," "extreme," "real," and "deep" as well as being used synonymously with "dread," "terror," and "anxiety." Emotional distress was described as immediate, extreme, and frequent, shown by collocation and concordance analyses. Individuals tended to use multiple emotional words collectively rather than single emotion labels to convey the depth and individual nature of the experience. The findings are consistent with what is otherwise known of the experience of anxiety for individuals with dementia, which is that anxiety is common. ${ }^{1,40,41}$ However, this study offered a more comprehensive description of anxiety than was presently available. ${ }^{1}$ The findings are consistent with a growing body of literature showing the importance of anxiety in dementia.

The self, others, and dementia: Distress was explained predominantly by individuals losing hold of themselves and losing their 
TABLE 5 Summary of all explanations for distress displayed as key concepts and sub-concepts

\begin{tabular}{|c|c|c|}
\hline Key Concepts & Sub-Concepts & Concept Description \\
\hline Self & $\begin{array}{l}\text { Loss of self } \\
\text { Can't }\end{array}$ & $\begin{array}{l}\text { Distress was caused by changes to an individual's stable sense of knowing themselves; feeling lost, empty and } \\
\text { akin to an object or alien, between different worlds and struggling to find meaning. "Drifting," "void," } \\
\text { "absence," "estrangement," "strangeness," and "disconnect" were described. A person's self was described as } \\
\text { being threatened, attacked, stolen or murdered. For some, the self became defined by damage and disability, a } \\
\text { loss of capabilities, professional and family roles, activity and active participation. }\end{array}$ \\
\hline Social position & $\begin{array}{l}\text { Judgment } \\
\text { Exclusion and } \\
\text { control } \\
\text { Burden }\end{array}$ & $\begin{array}{l}\text { Being positioned as worthless, criticized and negatively labelled caused distress. Individuals spoke of stigma } \\
\text { being attached to a dementia diagnosis and feared being judged as mad, stupid, childish, a liar, or dangerous. } \\
\text { They feared being excluded by others and society by not being consulted, informed, or understood by others } \\
\text { equally, being controlled by the actions of others caused distress. Individuals feared burdening others. }\end{array}$ \\
\hline Relational needs & $\begin{array}{l}\text { Alone } \\
\text { Cognitive } \\
\text { difficulties } \\
\text { Dependence }\end{array}$ & $\begin{array}{l}\text { Having relational needs that were unmet caused distress, which included the actual absence of relationships as } \\
\text { well as individuals interpreting that relations were absent or would be absent when needed; being forgotten, } \\
\text { abandoned or betrayed. Hence, individuals could not receive comfort from others when needed. }\end{array}$ \\
\hline Future & $\begin{array}{l}\text { Diagnosis } \\
\text { The future } \\
\text { Death }\end{array}$ & $\begin{array}{l}\text { Individuals assigned meaning to their dementia diagnosis that caused distress; they anticipated the loss of their } \\
\text { cognitive and physical abilities, their future as a whole and fearfully anticipated death. }\end{array}$ \\
\hline Physical environment & & $\begin{array}{l}\text { Distress was caused when the external world seemed confusing due to things being too fast, loud or bright, as } \\
\text { well as living in strange environments such as care settings. Some individuals described fear of getting lost, of } \\
\text { theft, or of coming to harm. }\end{array}$ \\
\hline Perception & & $\begin{array}{l}\text { Distress was caused by being cued in to a time and place from the past, which caused re-living of events, such as } \\
\text { past violence. Distress was caused by unusual perceptual experiences, including hallucinations of animals and } \\
\text { the room swaying. }\end{array}$ \\
\hline
\end{tabular}

capabilities, their future, freedom and control, their social world, and needing to turn to others for emotional care; hence, dementia raised all fundamental, human anxieties. ${ }^{42,43}$ The cognitive symptoms of dementia contributed to emotional distress only when an individual perceived themselves to be failing, being without value, being blamed as "mad" or "stupid" and when cognitive difficulties inhibited meaningful relationships with others. The model is consistent with theoretical perspectives of the psychosocial needs of individuals with dementia ${ }^{44}$ and with previous theoretical literature. ${ }^{40,45}$ The need for others at times of distress was considerable, which is in keeping with fundamental principles of psychotherapy, emotional wellbeing, and the subjective experiences of older adults. ${ }^{46}$ The findings are also supported by identity theories that state that a person defines themselves through a process of sense-making, or "self-making" with other people. ${ }^{47}$ The viewpoints presented in this review described the social world of individuals with dementia as stigmatizing. They described a transition from a valued identity, to one that was devalued and shameful. ${ }^{48}$ The dominating socially held view of dementia as negative and as existing within the person ${ }^{14}$ no doubt contributes to this distressing experience.

Therefore, from the wealth of evidence and the intensity of emotion expressed, severe threats to an individual's human need for identity, belonging, hope, and predictability were considerable preoccupations for at least some people with dementia.

\section{2 | Strengths and limitations}

Strengths: The best represented populations were individuals with a diagnosis of Alzheimer's disease, a mild severity of dementia, and residing within the community in the UK and USA. Whilst this limits the generalizability of the findings, individuals with mild dementia and Alzheimer's disease are greatest in number in these 2 countries, meaning these findings can be widely applied. ${ }^{49}$ The sensitive search strategy allowed some representation of a range of dementia severities, dementia diagnoses, countries, and living environments, which was considered to strengthen the generalizability of the findings. The inclusion of quantitative and qualitative studies in this mixed-methods review was also considered to be a strength. The number of studies was acceptable for both corpus-based and metaethnography analyses. The application of corpus-based linguistics to understand the language used to articulate emotional distress was original and introduced an objective analysis that identified patterns of communication that otherwise would have been difficult if not impossible to apprehend. The mixed-methods approach of quantitative analysis alongside qualitative analysis to interpret and make sense of language use in its context offered an overarching synthesis. This was otherwise missing from the research literature.

Limitations: The included texts might have missed some of the variability in how individuals have articulated distress. Notable examples are social media including diaries, blogs, and social networking and accounts that have not been captured in media. As only English-language reports were included, some reports in other languages such as French may have also been excluded; 8 non-English language reports were excluded. Similarly, the reference corpus used was essentially concerned with British English. ${ }^{26}$ Therefore, we acknowledge that a particular format of academic writing and a particular language register was represented in this study. ${ }^{33}$ The tool used to perform the quality assessments was not validated, which is acknowledged as a limitation. The Mixed Methods Appraisal Tool could be used in future reviews. ${ }^{50}$ This is particularly important given that quality appraisal is used to address the possible bias introduced with mixed study designs. ${ }^{23}$ It must be acknowledged that the differing accounts of emotional distress in this review will have been influenced by the viewpoint, of self-report and proxy-report. Furthermore, a critique of any synthesis is that the findings contain some level of interpretation of the original data, moving away from the original distress experience. ${ }^{51}$ The need for caution holds true for both analysis methods adopted. Corpus-based linguistics attempts to reveal what is 


\section{ACKNOWLEDGEMENTS}

Sponsor's role: The study was funded as part of S Petty's PhD studentship by The Retreat, York. The funding source did not determine the study design or the decision to submit the paper for publication. The authors wish to thank The Retreat, York for their generous support.

\section{CONFLICT OF INTEREST}

None declared. Finally, screening, quality appraisal, and synthesis would have benefited from multiple reviewers for the full sample of texts.

In line with these criticisms, we made efforts to optimize the validity of the study findings and remain grounded in the individual experiences of distress, employing quality appraisal, the use of second reviewers where feasible, a transparent process with a documentation trail, adherence to recommended methodology, and the use of real text quotations to exemplify conclusions drawn. ${ }^{51}$

\section{3 | Future research}

This review demonstrated that research into the emotional experiences of dementia could adopt more robust methodology, notably to enhance the reliability and validity of findings by discussing confounding variables and discussing the representativeness of the sample. In addition, the relationship between the author and sample should be considered to account for bias in the recorded accounts of individuals subjective experiences. Researchers could learn from the research into moderate-to-severe dementia presentations to increase confidence in representing this population more widely. Furthermore, future research should continue to explore solutions for conducting mixed studies reviews. The selection of the literature was made difficult by variability in methods, terminology, and article structure adopted in the social sciences. ${ }^{23,53}$ Searching of mixed studies is known to be time and resource intensive with a thorough screening process. However, the findings can address important unanswered questions, as in this review.

\subsection{Clinical implications}

These findings evidenced the experience of emotional distress for individuals with dementia, by presenting a dataset that moves beyond surmised or reduced notions of emotional distress. The findings showed that the voices of individuals with dementia outweighed the penumbra in this research area. These findings are relevant to clinicians as they attempt to improve the limited understanding of personal experiences of dementia and individual care needs which, in turn, can influence care planning. In particular, individuals have expressed that being consulted and receiving a timely diagnosis could reduce their distress. More generally, the results indicated that feeling valued by others, being able to depend upon others for emotional support, being able to anticipate a hopeful future, and maintaining purpose and a continuous sense of self could also reduce distress. This systematic review offers clarification of the emotional distress experienced by individuals with dementia, in response to the minimal attention sometimes paid to hearing their voice.

\section{FUNDING SOURCE}

The study was funded as part of S Petty's PhD studentship by The Retreat, York. The funding source did not determine the study design or the decision to submit the paper for publication.

\section{AUTHOR'S CONTRIBUTIONS}

S. Petty affirms that everyone who contributed significantly to the work has been listed as an author.

\section{ORCID}

Stephanie Petty (D) http://orcid.org/0000-0002-1453-3313

Tom Dening (i) http://orcid.org/0000-0003-3387-4241

\section{REFERENCES}

1. Seignourel PJ, Kunik ME, Snow L, Wilson N, Stanley M. Anxiety in dementia: a critical review. Clin Psychol Rev. 2008;28(7):1071-1082.

2. Verhey FRJ, Visser PJ. Phenomenology of depression in dementia. Int Psychogeriatr. 2000;12(S1):129-134.

3. Petty S, Dening T, Coleston DM, Griffiths A. Dementia: beyond disorders of mood. Aging Ment Health. In press.

4. Kitwood T. The experience of dementia. Aging Ment Health. 1997; $1(1): 13-22$

5. Miesen BML. Alzheimer's disease, the phenomenon of parent fixation and Bowlby's attachment theory. Int J Geriatr Psychiatry. 1993; 8(2):147-153.

6. Davenhill R. Looking Into Later Life: A Psychoanalytic Approach to Depression and Dementia in Old Age. London: Karnac Books; 2007.

7. Evans S. 'Beyond forgetfulness': how psychoanalytic ideas can help us to understand the experience of patients with dementia. Psychoanal Psychother. 2008;22(3):155-176.

8. Malloy L. Thinking about dementia-a psychodynamic understanding of links between early infantile experience and dementia. Psychoanal Psychother. 2009;23(2):109-120.

9. Orgeta V, Qazi A, Spector A, Orrell M. Psychological treatments for depression and anxiety in dementia and mild cognitive impairment: systematic review and meta-analysis. Br J Psychiatry. 2015;207(4):293-298.

10. Magai C, Cohen C, Gomberg D, Malatesta C, Culver C. Emotional expression during mid- to late-stage dementia. Int Psychogeriatr. 1996;8(3):383-395.

11. National Institute for Health and Clinical Excellence. Supporting People with Dementia and Their Carers in Health and Social Care (CG42). London: National Institute for Clinical Excellence and Social Care Institute for Excellence; 2006.

12. Johansson ÅK, Grimby A. Grief among demented elderly individuals: a pilot study. Am J Hosp Palliat Med. 2013;30(5):445-449.

13. Bartlett R, Windemuth-Wolfson L, Oliver K, Dening T. Suffering with dementia: the other side of "living well". Int Psychogeriatr. 2017; 29(2):177-179. 
14. World Health Organization. Dementia: Factsheet 2016. http://www. who.int/mediacentre/factsheets/fs362/en/. Accessed 23 January, 2017.

15. van der Linde RM, Dening T, Stephan BC, et at. Longitudinal course of behavioural and psychological symptoms of dementia: systematic review. Br J Psychiatry. 2016;209(5):366-377.

16. Pilkonis PA, Choi SW, Reise SP, et al. Item banks for measuring emotional distress from the Patient-Reported Outcomes Measurement

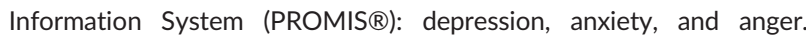
Assessment. 2011;18(3):263-283.

17. Elliot V, Williams A, Meyer J. Supporting staff to care for people with dementia who experience distress reactions. Nurs Older People. 2014;26(7):22-26.

18. Fujii M, Butler JP, Hirazakura A, Sasaki H. Mini-emotional state examination for dementia patients. Geriatr Gerontol Int. 2014;14(2):508-513.

19. Jones S, Mitchell G. Assessment of pain and alleviation of distress for people living with a dementia. Mental Health Practice. 2015; 18(10):32-36

20. National Institute for Health and Clinical Excellence. Dementia: support in health and social care (QS1). National Institute for Health and Care Excellence; 2010.

21. Care Quality Commission. Care Update Issue 2: March. Care Quality Commission 2013.

22. Tappen RM, Williams C. Attribution of emotion in advanced Alzheimer's disease: family and caregiver perspectives. Am J Alzheimers Dis Other Demen. 1998;13(5):257-264.

23. Petticrew M, Roberts H. Systematic Reviews in Social Sciences: A Practical Guide. Oxford: Blackwell Publishing; 2006.

24. Jamal F, Fletcher A, Harden A,-et at. The school environment and student health: a systematic review and meta-ethnography of qualitative research. BMC Public Health. 2013;13(1):798-808.

25. Noblit GW, Hare RD. Meta-Ethnography: Synthesizing Qualitative Studies. Newbury Park: Sage Publications, Inc; 1988.

26. Baker P. Sociolinguistics and Corpus Linguistics. Edinburgh: Edinburgh University Press; 2010.

27. Harvey K. Disclosures of depression: using corpus linguistics methods to examine young people's online health concerns. Int J Corpus Linguist. 2012;17(3):349-379.

28. Harvey K, Koteyko N. Exploring Health Communication: Language in Action. Oxon: Routledge; 2012.

29. McEnery T, Hardie A. Corpus Linguistics: Method, Theory and Practice. Cambridge: Cambridge University Press; 2012.

30. Scott M. WordSmith Tools 7.0: Windows software for finding word patterns 2017a. http://www.lexically.net/wordsmith/downloads/. Accessed 2 February, 2017.

31. Scott M. Introduction to WordSmith Tools. Version: 7.0 2017b. http:// lexically.net/downloads/version7/HTML/index.html?getting_started. htm. Accessed 3 February, 2017.

32. Burnard L. About the British National Corpus: University of Oxford; 2009 [Available from: http://www.natcorp.ox.ac.uk/corpus/index.xml. Accessed 2 February, 2017.

33. Hunston S. Corpora in Applied Linguistics. Cambridge: Cambridge University Press; 2002.

34. Britten N, Campbell R, Pope C,-et at. Using meta ethnography to synthesise qualitative research: a worked example. J Health Serv Res Policy. 2002;7(4):209-215.

35. Campbell R, Pound P, Morgan M, et al. Evaluating meta ethnography: systematic analysis and synthesis of qualitative research. Health Technol Assess. 2011;15(43):i-165.
36. Campbell R, Pound P, Pope C, et al. Evaluating meta-ethnography: a synthesis of qualitative research on lay experiences of diabetes and diabetes care. Soc Sci Med. 2003;56(4):671-684.

37. Pound P, Britten N, Morgan M, et al. Resisting medicines: a synthesis of qualitative studies of medicine taking. Soc Sci Med. 2005;61(1):133-155.

38. Toye F, Seers K, Allcock N, et at. Meta-ethnography 25 years on: challenges and insights for synthesising a large number of qualitative studies. BMC Med Res Methodol. 2014;14(1):80-93.

39. France EF, Ring N, Thomas $\mathrm{R}$, et at A methodological systematic review of what's wrong with meta-ethnography reporting. BMC Med Res Methodol. 2014;14(1):119-134.

40. Evans S, Garner J. Talking Over the Years: A Handbook of Dynamic Psychotherapy with Older Adults. Hove: Bruner Routledge; 2004.

41. Alzheimer's Society. Dementia 2014: Opportunity for change2014.

42. Lieberman MA, Tobin SS. The Experience of Old Age: Stress, Coping, and Survival. New York: Basic Books; 1983.

43. Yalom ID. Existential Psychotherapy. New York: Basic Books; 1980.

44. Kasl-Godley J, Gatz M. Psychosocial interventions for individuals with dementia: an integration of theory, therapy, and a clinical understanding of dementia. Clin Psychol Rev. 2000;20(6):755-782.

45. Davenhill R. Psychoanalysis and old age. In: Woods B, Clare L, eds. Handbook of the Clinical Psychology of Ageing. New York: John Wiley \& Sons Ltd; 2008.

46. Lazarus LW. Self psychology and psychotherapy with the elderly: theory and practice. J Geriatr Psychiatry. 1980;13:69-88.

47. Urrieta L. Identity production in figured worlds: how some Mexican Americans become Chicana/o activist educators. Urban Rev. 2007;39(2):117-144.

48. Schwartz G, Merten GS. Social identity and expressive symbols: the meaning of an initiation ritual. Am Anthropol. 1968;70(6):1117-1131.

49. Winblad B, Amouyel P, Andrieu S, et al. Defeating Alzheimer's disease and other dementias: a priority for European science and society. Lancet Neurol. 2016;15(5):455-532.

50. Pluye P, Robert E, Cargo M, et al. Proposal: a mixed methods appraisal tool for systematic mixed studies reviews 2011. http:// mixedmethodsappraisaltoolpublic.pbworks.com. Accessed 21 December, 2017.

51. Sandelowski M, Barroso J. Handbook for Synthesizing Qualitative Research. New York: Springer Publishing Company; 2006.

52. Atkins S, Lewin S, Smith $\mathrm{H}$, et at. Conducting a meta-ethnography of qualitative literature: lessons learnt. BMC Med Res Methodol. 2008;8(1):21-30.

53. Forbes A, Griffiths P. Methodological strategies for the identification and synthesis of 'evidence' to support decision-making in relation to complex healthcare systems and practices. Nurs Inq. 2002;9(3):141-155.

\section{SUPPORTING INFORMATION}

Additional Supporting Information may be found online in the supporting information tab for this article.

How to cite this article: Petty S, Harvey K, Griffiths A, Coleston DM, Dening T. Emotional distress with dementia: A systematic review using corpus-based analysis and metaethnography. Int J Geriatr Psychiatry. 2018;1-9. https://doi. org/10.1002/gps.4870 